\title{
Effect of ischaemia on somatosensory evoked potentials in diabetic patients
}

\author{
TOMÁS LÓPEZ-ALBURQUERQUE, ANGEL GARCÍA MIGUEL, \\ JUAN-JOSÉ RUIZ EZQUERRO, JOSÉ DE PORTUGAL ALVAREZ
}

From the Department of Internal Medicine, the Division of Neurology, Hospital Clínico Universitario, Salamanca, Spain

SUMMARY The nerve action potential at the elbow and somatosensory evoked potentials (SEPs) at the scalp were recorded over 30 minutes of tourniquet-induced limb ischaemia in 10 diabetic patients and 10 controls. According to the SEP changes, an increased resistance to nerve ischaemia in diabetic patients was observed. The pathways involved in SEP conduction are discussed.

It has been reported that diabetic patients retain their vibratory perception much longer than normal individuals during ischaemia. ${ }^{1}$ This phenomenon has later been demonstrated for touch and pain as well. ${ }^{2}$ Electrophysiological studies have shown abnormal preservation of the nerve action potential (NAP) after 30 minutes of ischaemia in diabetic patients. ${ }^{3-6}$ However, the simultaneous changes in the NAP and somatosensory evoked potentials (SEPs) during ischaemia has not yet been investigated in patients with diabetes mellitus. The aim of the present report was to evaluate these changes in a group of diabetic patients.

\section{Patients and methods}

The studies were carried out on 10 diabetic patients, aged 18 to 54 years (mean, 36 years), with informed consent, and 10 heathy volunteers, aged 22 to 49 years (mean, 33 years). Six patients were insulin-dependent diabetics and four non insulin-dependent diabetics. Mean duration of diabetes was 4.5 years (range 4 months to 7 years). Clinical or electrophysiological signs of polyneuropathy were detected in seven patients. A sphygmomanometer cuff $(14 \mathrm{~cm}$ wide) was placed on the right arm with its distal border about $5 \mathrm{~cm}$ above the antecubital fossa, and was inflated to $80 \mathrm{~mm} \mathrm{Hg}$ above systolic blood pressure.

Sensory examination (light touch, pinprick, two-point discrimination, joint sense and vibration), the NAPs at the elbow and SEPs at the scalp overlying the contralateral pari-

This study was presented at the XII Congress of the International Diabetes Federation, Madrid 1985.

Address for reprint requests: $\operatorname{Dr} \mathrm{T}$ López-Alburquerque, Department of Internal Medicine, Division of Neurology, Hospital Clínico Universitario, Salamanca, Spain.

Received 1 November 1985 and in revised form 9 May 1986. Accepted 23 June 1986 etal cortex were recorded every 5 minutes for 30 minutes of induced limb ischaemia and for another 30 minutes after release of the cuff. Two saline soaked felt pad electrodes $(1 \cdot 1 \mathrm{~cm}$ apart) (Medelec $\mathrm{EL} 210 \mathrm{M})$ and two $\mathrm{Ag} / \mathrm{AgCl}$ disk electrodes ( $1 \mathrm{~cm}$ of diameter) were used to record NAPs and SEPs, respectively. The recording electrode for SEPs was placed at $C_{3}^{\prime}\left(2 \mathrm{~cm}\right.$ behind $\left.C_{3}\right)$ (International 10-20 system), referenced to a midfrontal electrode $(\mathrm{Fz})$. A two-channel Medelec MS6 electromyograph was used. The right median nerve was percutaneously stimulated at the wrist with an intensity sufficient to elicit a visible twitch in thenar muscles. Stimuli (square waves of $0.2 \mathrm{~ms}$ ) were delivered at a rate of $5 \mathrm{~Hz}$. The number of responses averaged was 128 . The time analysed was $100 \mathrm{~ms}$. Filter setting of $3 \cdot 2-3200 \mathrm{~Hz}$ were used. NAP latency was measured at the first positive peak. Amplitudes were measured peak-to-peak (N19/P22 for the N19 component) and expressed as the percentage value of the pre-ischaemic determination. For statistical evaluation of the results Student's $t$ test and linear correlations were applied.

\section{Results}

\section{(1) Control group}

In all normal subjects the following baseline SEP components could be identified: N19, P22, N32, P42 and N58 (fig 1). A pre-ischaemic NAP at the elbow was recorded in the 10 controls.

The amplitudes of the NAP and SEP components tended to decrease as a function of the duration of ischaemia (fig 1). Although the NAP decreased more rapidly than N19 between 10 and 20 minutes, in all 10 controls both potentials were abolished before 30 minutes had elapsed (fig 2). Loss of the NAP, N19 component and proprioceptive sensation occurred simultaneously in eight out of 10 subjects (fig 1 ). The later components of the SEP were more resistant to ischaemia. When these could no longer be recorded, 
Effect of ischaemia on somatosensory evoked potentials in diabetic patients

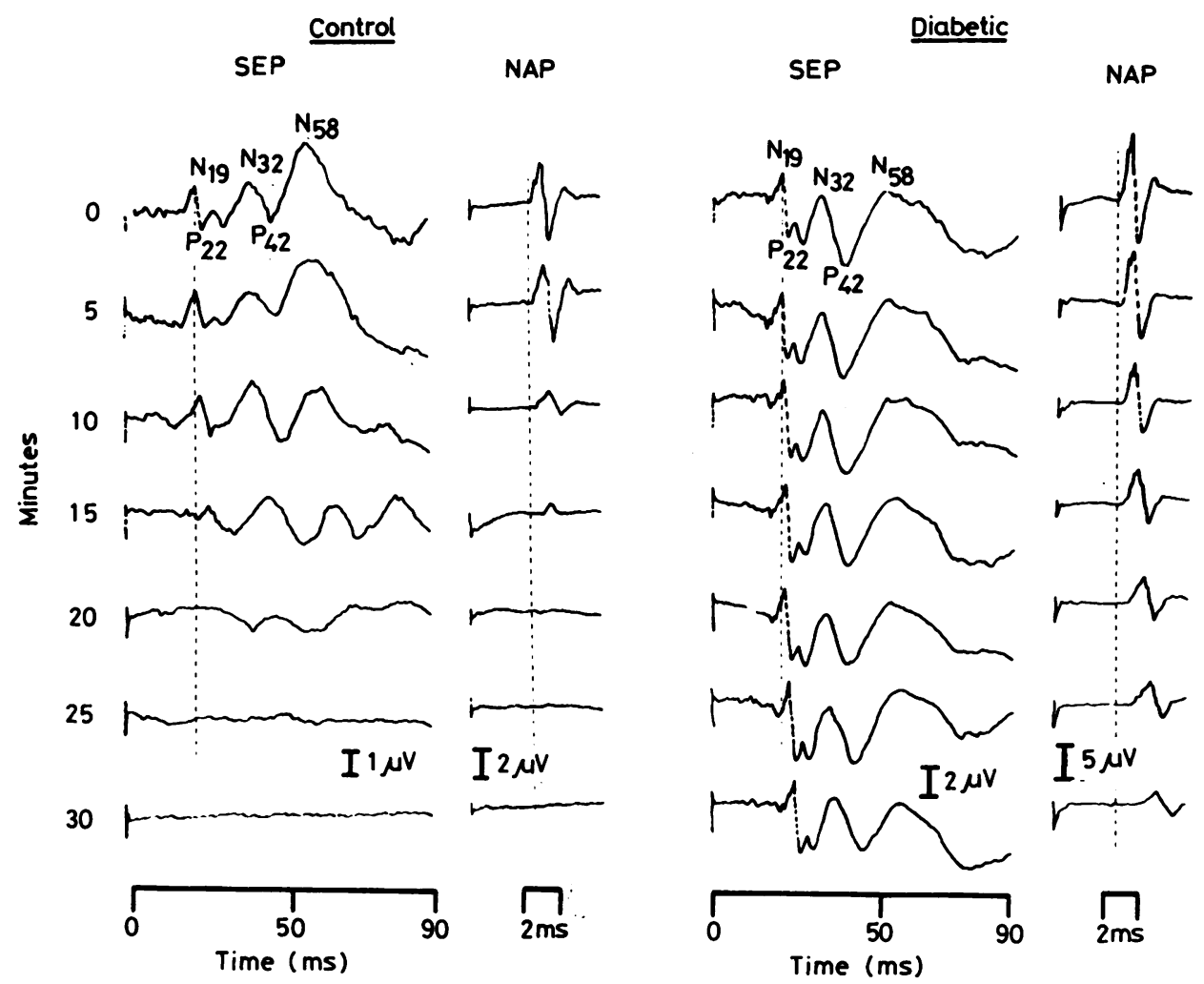

Fig 1 The SEP and NAP in one diabetic and a control. The persistence of both SEP and NAP over 30 minutes of ischaemia in diabetic can be observed.
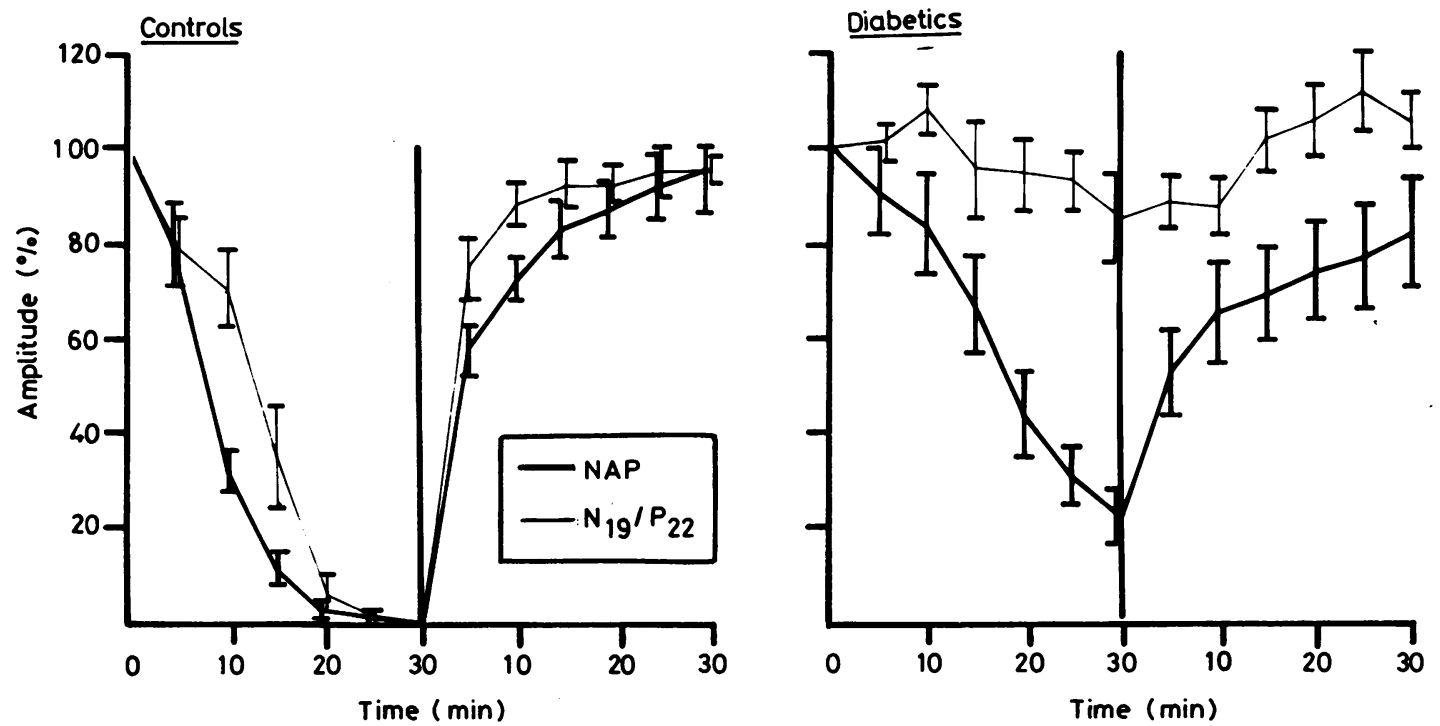

Fig 2 Changes in amplitude of the NAP and N19 component in controls and diabetics during and after 30 minutes of ischaemia (mean $\pm S E M)$. 
complete sensory loss appeared. A rapid recovery of the amplitudes took place early in the course of the post-ischaemic period (fig 2).

All SEP peaks and the NAP presented a progressive increase in latency during ischaemia (fig 3). Absolute values of the NAP and N19 latencies are shown in table 1. The decreased absolute mean latency of the NAP at 20 minutes with respect to the mean value obtained at 15 minutes was due to the abolishing of the potential in the subjects with longer baseline latencies. The pre-ischaemic mean values of these latter subjects were significantly higher than those of the patients retaining the NAP at 20 minutes: $3.7 \pm 0.4$ and $3.3 \pm 0.1 \mathrm{~ms}(\mathrm{SD})$, respectively ( $\mathrm{p}<$ $0.05)$. A correlation between wrist-elbow distances and NAP latencies was observed $(r=0.78)(p<$ 0.01 ). When the mean increments in latency of the NAP and N19 were compared, a statistically significant difference was observed from the beginning of ischaemia ( $p<0.001)$ (fig 4). Except for the

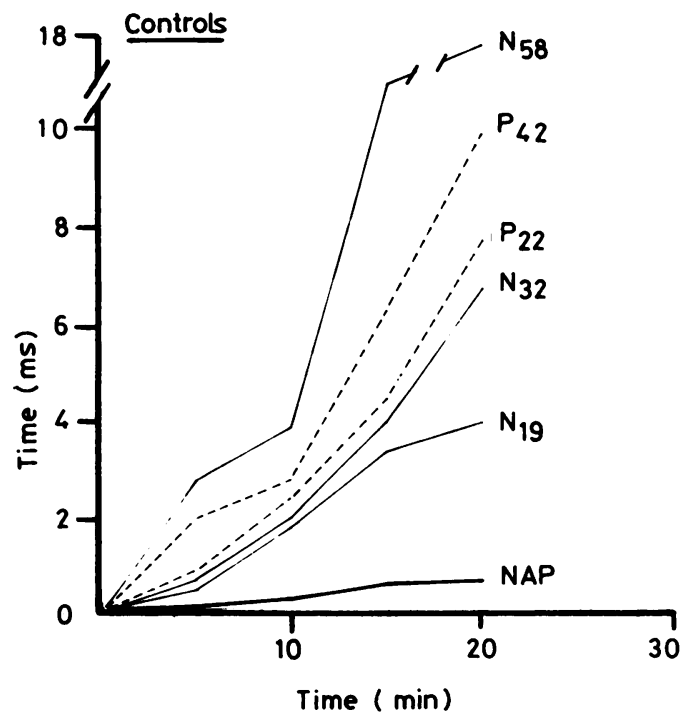

N58 component, there was no significant difference between delayed latencies of the remaining SEP peaks.

\section{(2) Diabetic patients}

In the 10 diabetics, the NAP disappeared only in one (insulin-dependent diabetic of 4 months of evolution) before the end of 30 minutes of ischaemia (at 20 minutes). In this patient, all SEP components were recorded at 25 minutes, after which the test had to be suspended owing to severe pain. In the remaining diabetic patients, the NAP and SEP could be recorded through the test (fig 1).

The decreased amplitude of the NAP and N19 component is shown in fig 2 . The NAP amplitude was reduced by $77 \cdot 7 \%$ at 30 minutes. In contrast, minimal changes were observed in N19 and the remaining SEP components.

As in the control group, a significant difference ( $p$

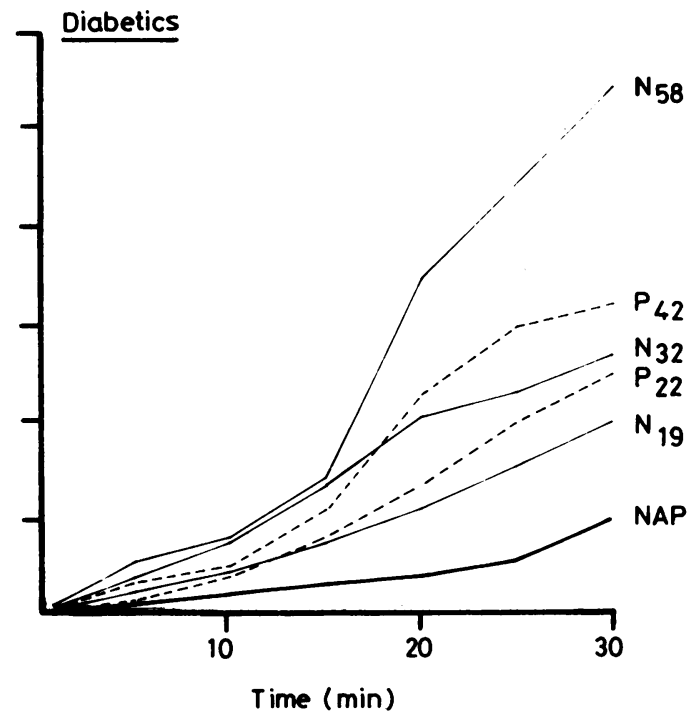

Fig 3 Increasing latencies of the NAP and SEP peaks in controls and diabetics during 30 minutes of ischaemia.

Table 1 Latencies of the nerve action potential (NAP) and N19 peak during ischaemia in controls (Mean \pm SEM)

\begin{tabular}{|c|c|c|c|c|c|c|}
\hline \multirow[b]{2}{*}{$\begin{array}{l}\text { Time } \\
\text { (minutes) }\end{array}$} & \multicolumn{3}{|l|}{$N A P$} & \multicolumn{3}{|l|}{$N 19$} \\
\hline & $\begin{array}{l}\text { Absolute } \\
\text { values (ms) }\end{array}$ & Increase (\%) & $n^{*}$ & $\begin{array}{l}\text { Absolute } \\
\text { values (ms) }\end{array}$ & Increase (\%) & $n^{*}$ \\
\hline $\begin{array}{r}0 \\
5 \\
10 \\
15 \\
20 \\
25 \\
30\end{array}$ & $\begin{array}{l}3.5 \pm 0.1 \\
3.6 \pm 0.1 \\
3.9 \pm 0.1 \\
4.2 \pm 0.2 \\
4.0 \pm 0.2 \\
4.1 \pm 0.2 \\
-\end{array}$ & $\begin{array}{r}-2.5 \pm 0.9 \\
10.9 \pm 2.3 \\
18.5 \pm 4.7 \\
20.1 \pm 3.1 \\
25.7 \pm 5.0 \\
-\end{array}$ & $\begin{array}{r}10 \\
10 \\
10 \\
8 \\
4 \\
2 \\
0\end{array}$ & $\begin{array}{l}19.2 \pm 0.4 \\
19.7 \pm 0.3 \\
21.0 \pm 0.4 \\
22.5 \pm 0.5 \\
22.7 \pm 0.2 \\
23.2 \pm 0.0 \\
-\end{array}$ & $\begin{array}{l}-3.3 \pm 0.6 \\
9.2 \pm 1.0 \\
18.0 \pm 1.5 \\
21.2 \pm 3.5 \\
22.0 \pm 0.0 \\
-\end{array}$ & $\begin{array}{r}10 \\
10 \\
10 \\
8 \\
3 \\
1 \\
0\end{array}$ \\
\hline
\end{tabular}

* Number of the subjects in whom the potential could be recorded. 


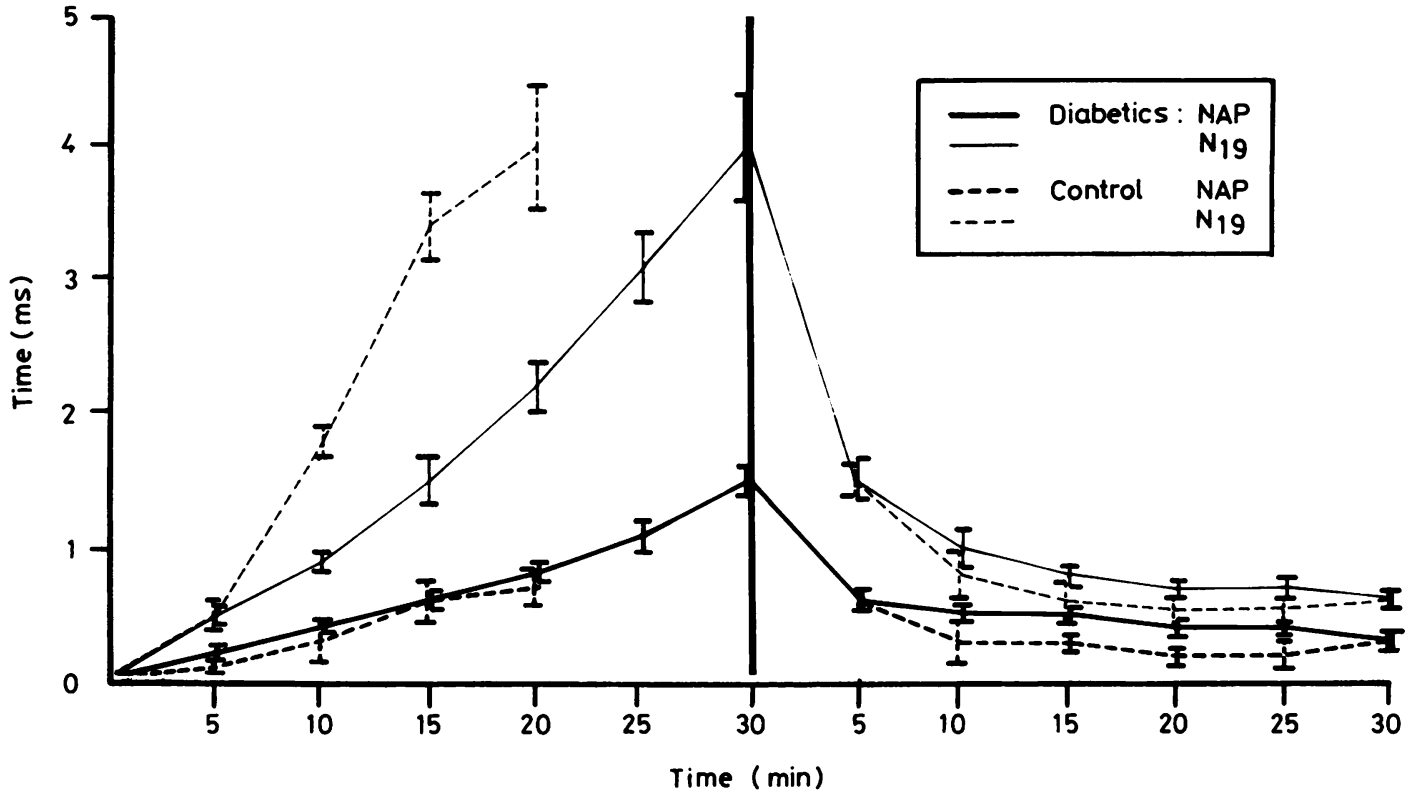

Fig 4 Delayed latencies of the NAP and N19 peak in controls and diabetics during and after 30 minutes of ischaemia (mean $\pm S E M)$.

Table 2 Latencies of the nerve action potential (NAP) and N19 peak during ischaemia in diabetics (Mean $\pm S E M)$

\begin{tabular}{|c|c|c|c|c|c|c|}
\hline \multirow[b]{2}{*}{$\begin{array}{l}\text { Time } \\
\text { (minutes) }\end{array}$} & \multicolumn{3}{|l|}{$N A P$} & \multicolumn{3}{|l|}{$N 19$} \\
\hline & $\begin{array}{l}\text { Absolute } \\
\text { values (ms) }\end{array}$ & Increase (\%) & $n^{*}$ & $\begin{array}{l}\text { Absolute } \\
\text { values (ms) }\end{array}$ & Increase (\%) & $n^{*}$ \\
\hline $\begin{array}{r}0 \\
5 \\
10 \\
15 \\
20 \\
25 \\
30\end{array}$ & $\begin{array}{l}3.7 \pm 0.1 \\
3.8 \pm 0.1 \\
4.0 \pm 0.1 \\
4.2 \pm 0.2 \\
4.4 \pm 0.2 \\
4.7 \pm 0.2 \\
5.1 \pm 0.2\end{array}$ & $\begin{array}{r}-4.4 \pm 0.5 \\
9.7 \pm 0.9 \\
15 \cdot 6 \pm 1.2 \\
20.7 \pm 2.0 \\
29 \cdot 3 \pm 3.1 \\
40.1 \pm 4.5\end{array}$ & $\begin{array}{r}10 \\
10 \\
10 \\
10 \\
9 \\
9 \\
9\end{array}$ & $\begin{array}{l}19.8 \pm 0.4 \\
20.3 \pm 0.4 \\
20.6 \pm 0.4 \\
21.3 \pm 0.4 \\
22.0 \pm 0.4 \\
22.9 \pm 0.3 \\
23.5 \pm 0.3\end{array}$ & $\begin{array}{r}\overline{2} .4 \pm 0.3 \\
4.4 \pm 0.3 \\
7.7 \pm 0.8 \\
11.2 \pm 0.9 \\
15.2 \pm 1.4 \\
21.1 \pm 2.0\end{array}$ & $\begin{array}{r}10 \\
10 \\
10 \\
10 \\
10 \\
9 \\
9\end{array}$ \\
\hline
\end{tabular}

*Number of the patients in whom the potential could be recorded.

$<0.001$ ) between the NAP and N19 delayed latencies was observed (figs 3 and 4). The absolute values of the NAP and N19 component during ischaemia are summarised in table 2 . There was no statistically significant difference between delayed latencies of the different SEP peaks (fig 3).

During the first 20 minutes of ischaemia, the increments in latency of the NAP were similar in the diabetics and controls (fig 4). However, from 5 minutes of ischaemia the N19 peak latencies of the diabetic patients were significantly less delayed than those of the control group (p < 0.001) (fig 4).

\section{Discussion}

We have observed the existence of an abnormal resistance to ischaemia in diabetic nerves, ${ }^{1-6}$ since in nine out of the 10 diabetic patients studied both the NAP and SEP could still be recorded at 30 minutes. In contrast, all normal subjects lost these potentials before this time.

In controls, the percentage attenuation of the N19 amplitude tended to decrease at a slower rate than that of the NAP. However, both these potentials and proprioceptive sensation disappeared simultaneously in eight subjects. Similar results have been reported previously, ${ }^{78}$ suggesting that the $\mathrm{N} 19$ component may be carried by large myelinated fibres considered to be the most sensitive to ischaemia. ${ }^{8-10}$ The SEP of longer latencies disappeared later. This greater resistance to ischaemia suggest that their conduction may rely on smaller diameter fibres than the N19 component. ${ }^{78}$ The amplitude changes of our control group are in accordance with the clinical and experi- 
mental findings showing a mixed participation (dorsal column/medial lemniscal system and spinothalamic pathway) in SEP conduction. ${ }^{11-14}$

A greater divergence between the N19 and NAP amplitude curves was observed in diabetic patients. Whereas the NAP amplitude was reduced by $\mathbf{7 7 . 7 \%}$ at 30 minutes of ischaemia, no significant changes were shown by $\mathrm{N} 19$ component. Although the slower decrease of N19 amplitude curves than the NAP in diabetics and controls may suggest two different pathways for both potentials, this finding could be explained assuming that the $\mathrm{N} 19$ component may be carried by a small number of nerve fibres, owing to integration and amplification of afferent impulses in the CNS. ${ }^{15}$ In contrast, the NAP amplitude depends on the synchronisation of peripheral nerve impulses. ${ }^{1617}$ This may be the reason why the control subjects with shorter wrist-elbow distances retained the NAP for longer during ischaemia. ${ }^{1018-20}$

Similarly, the greater resistance to ischaemia of late components of SEPs observed in our control group could be due to a more synaptic amplification of these waves than N19, allowing the former to be recorded when only a few large fibres are still conducting. This would be an alternative explanation to the dual conduction pathway referred to above, bearing in mind the possibility that the intensity of the stimulus applied to our subjects is probably insufficient to stimulate a large number of small fibres.

It seems that differences in amplitude changes of the NAP and N19 component between diabetics and controls may be one of rapidity and not of degree. In fact, if in diabetics the ischaemic time is prolonged until a point where a peripheral conduction block is achieved, one could expect to obtain a convergence of the NAP and N19 amplitude curves at zero, as in normal subjects.

Unlike amplitude changes, delayed latencies of the NAP and N19 peak during ischaemia suggest different pathways for both these potentials. Indeed, the increase in absolute latency of the N19 peak was greater than the NAP in diabetics and controls (more than 4 times at 20 minutes of ischaemia in these latter). Since the length of pathway made ischaemic was similar for both potentials, a minor difference between their delayed latencies was to be expected. Yamada et $a l^{\mathbf{8}}$ observed a similar delay for Erb's potential and N19 latencies during ischaemia. These authors stated that both potentials are primarily carried by large myelinated fibres. Because the first positive peak of the NAP is thought to correspond to the large-diameter fast-conducting fibres, ${ }^{21}$ one could argue from our results that N19 may be subserved by smaller diameter fibres than the NAP, probably by Group II fibres, conducting in the forearm not faster than approximately $75 \mathrm{~m} / \mathrm{s}^{22}$ If these two different pathways for both NAP and N19 are assumed, it could be postulated (for linking amplitude and latency changes) that while conduction block in the largest fibres is occurring fairly rapidly the smaller fibres are just being delayed.

Although the conduction changes in ischaemic nerves seem to be due mainly to hypoxia, ${ }^{41018}$ mechanical factors cannot be ruled out. ${ }^{23}$ Unlike the NAP, the N19 pathway was compressed by the tourniquet. This additional factor may contribute to the greater delayed latency of the N19 peak, since, as has been reported, ${ }^{23}$ large nerve fibres are more sensitive to compression than ischaemia. Experimental evidence exists of nerve lesions produced by pneumatic tourniquet compression. ${ }^{24}$ However, the early postischaemic recovery and the brief and relatively slight compression applied to the arm of our subjects do not suggest a structural nerve lesion as the main causative factor of the SEP changes.

The NAP latencies of diabetics and controls were similarly delayed. Less delayed latencies in diabetics than controls have been usually reported. ${ }^{2-46}$ However, Castaigne et $\mathrm{al}^{25}$ found a similar phenomenon to our own in uraemic patients, suggesting the possibility of "a greater influence of ischaemia upon nerve excitability than on nerve conduction". On the contrary, the N19 latencies of our diabetic patients were significantly less delayed than those of the control group from 5 minutes of ischaemia. This different response to ischaemia of fibres conducting the NAP and N19 component is consistent with the suspicion that the main fibre group determining the latency of the NAP is not the same as that which determines the N19 peak.

In diabetics there was no significant difference between delayed latencies of the N19 and the remaining SEP peaks during ischaemia. In the control group, only the N58 was significantly delayed in relation to the other SEP peaks. This component showed great fluctuations in latency and morphology during ischaemia. Our results contrast with those of Yamada et $a l^{8}$ who identified two groups from the latency changes during ischaemia: one formed by Erb's potential, early SEP and the N19 component, and another composed of the components of longer latency, the increments in latency of this latter group being greater than those of the former. They suggest different pathways for these two groups.

The increased resistance of diabetic nerves to ischaemic conduction block is unknown. It could, however, be related to metabolic control of diabetes. 262627 This phenomenon, which is not specific to diabetes mellitus, ${ }^{202528-31}$ is probably the result of many factors. ${ }^{32}$ It may be due to a reduced metabolic need of impulse conduction derived from a slight depolarisation of diabetic nerves secondary to 
an abnormal function of the sodium pump caused by a defect in sodium-potassium ATPase. ${ }^{33}$ The basic abnormality remains unclear. However, an excessive accumulation of sorbitol ${ }^{34}$ and a reduced myoinositol concentration $^{35}$ in diabetic nerves seem to be involved.

From the SEP study, the existence may be inferred of an abnormally increased resistance to ischaemia of diabetic nerves, as was to be expected. However, it is difficult to arrive at a firm conclusion about the SEP pathway conduction from our findings, because there is a certain disparity between latency and amplitude changes. It could be due to a different influence of ischaemia on these two variables. Nevertheless, the latency changes from our diabetic and control groups suggest (if additional compressive factors on SEP pathway are not taken into account) that the N19 component is not mainly carried by the same large myelinated fast-conducting fibres originating the first positive peak of the NAP. On the contrary, the N19 and the following components of the SEP included in approximately the first $45 \mathrm{~ms}$ seem to be conducted through the same pathway.

\section{References}

1 Steiness I. Vibratory perception in diabetics during arrested blood flow to the limb. Acta Med Scand 1959;163:195-205.

2 Gregersen G. A study of peripheral nerves in diabetic subjects during ischaemia. J Neurol Neurosurg Psychiatry 1968;31:175-81.

3 Castaigne P, Cathala HP, Dry J, Mastropaolo C. Les résponses des nerfs et des muscles à des stimulations électriques au cours d'une épreuve de garrot ischémique chez l'homme normal et chez le diabetique. Rev Neurol (Paris) 1966;115:61-6.

4 Seneviratne KN, Peiris OA. The effect of ischaemia on the excitability of sensory nerves in diabetes mellitus. $J$ Neurol Neurosurg Psychiatry 1968;31:348-53.

5 Cruz Martínez A, Guillén M, Laborda E. Efectos de treinta minutos de isquemia sobre latencia sensitiva $y$ potencial del nervio mediano en sujetos normales y enfermos diabéticos. Rev Clin Esp 1974;132:337-46.

6 Horowitz SM, Ginsberg-Fellner F. Ischemia and sensory nerve conduction in diabetes mellitus. Neurology 1979;29:695-704.

7 Obeso JA, Martí-Massó JF, Remirez MV, Carrera N, Teijeira J. Vias y sistemas implicados en el origen del potencial evocado somatoseneorial en el hombre. Rev Clin Esp 1979;155:435-8.

8 Yamada T, Muroga T, Kimura J. Tourniquet-induced ischemia and somatosensory evoked potentials. $\mathrm{Neu}$ rology 1981;31:1524-9.

9 Gasser HS. Conduction in nerves in relation to fibres types. Res Publ Assoc Res Nerv Ment Dis 1935;15:35-59.

10 Magladery JW, McDougal DB Jr, Stoll J. Electrophysiological studies of nerve and reflex activity in normal man. II. The effects of peripheral ischemia. Bull Johns Hopkins Hosp 1950;86:291-312.

11 Alajouanine T, Scherrer J, Barbizet J, Calvet J, Verley R. Potentiels atteints de troubles somesthésiques. Rev Neurol (Paris) 1958;98:757-62.

12 Anderson SA, Norrsell K, Norrsell U. Spinal pathways projecting to the cerebral first somatosensory area in the monkey. $J$ Physiol (Lond) 1972;225:589-97.

13 Katz S, Martin HF, Blackburn JG. The effects of interaction between large and small diameter fibre systems on the somatosensory evoked potentials. Electroencephalogr Clin Neurophysiol 1978;45:45-52.

14 Simpson RK, Blackburn JG, Martin HF, Katz S. Peripheral nerve fibre and spinal cord pathway contributions to the somatosensory evoked potentials. Exp Neurol 1981;73:700-15.

15 Desmedt JE. Somatosensory cerebral evoked potential in man. In: Remond A, ed. Handbook of Electroencephalography and Clinical Neurophysiology. Amsterdam: Elsevier, vol 9, 1971:55-82.

16 Buchthal F, Rosenfalck A. Sensory potentials in polyneuropathy. Brain 1971;94:241-62.

17 Jewett DL, Walden CA, Chimento TC, Morris JH. Effects of acute nerve compression on conduction of impulse trains of increasing frequency. $J$ Neurol $S c i$ 1985;67:187-99.

18 Cathala H-P, Scherrer J. Modifications du potential de nerf, sous l'influence dún brassard ischemiant chez l'homme. Rev Neurol (Paris) 1963;108:201-4.

19 Fox JL, Kenmore PI. The effect of ischemia on nerve conduction. Exp Neurol 1967;17:403-19.

20 Caruso G, Labianca O, Ferrannini E. Effect of ischaemia on sensory potentials of normal subjects of different ages. J Neurol Neurosurg Psychiatry 1973;36:455-66.

21 Buchthal F, Rosenfalck A. Evoked action potentials and conduction velocity in human sensory nerves. Brain Res 1966;3:1-122.

22 Jones SL. Somatosensory evoked potentials: the normal waveform. In: Halliday AM, ed. Evoked Potentials in Clinical Testing. London: Churchill Livingstone, 1982:393-427.

23 Gelfan S, Tarlov IM. Physiology of spinal cord, nerve root and peripheral nerve compression. Am J Physiol 1955;185:217-29.

24 Ochoa J, Fowler TJ, Gilliatt RW. Anatomical changes in peripheral nerves compressed by a pneumatic tourniquet. J Anat 1972;113:433-55.

25 Castaigne P, Cathala H-P, Beaussart-Boulengé L, Petrover $M$. Effect of ischaemia on peripheral nerve function in patients with chronic renal failure undergoing dialysis treatment. J Neurol Neurosurg Psychiatry 1972;35:631-7.

26 Steiness I. Influence of diabetic status on vibratory perception during ischaemia. Acta Med Scand 1961;170:319-38.

27 Mauro AM, Guidi M, Pelliccioni G, Mercante O, Valazzi C. RRG, VEP and SEP modifications during ischemia in diabetic subjects. Electroencephalogr Clin Neurophysiol (Suppl) 1985;61:91.

28 Christensen NJ, Ørskov H. Vibratory perception during ischaemia in uraemic patients and in subjects with mild carbohydrate intolerance. $J$ Neurol Neurosurg 
Psychiatry 1969;32:519-24.

29 Seneviratne KN, Peiris OA. Peripheral nerve function in chronic liver disease. J Neurol Neurosurg Psychiatry 1970;33:609-14.

30 Shahani B, Davies-Jones GAB, Russell WR. Motor neurone disease. Further evidence for an abnormality of nerve metabolism. J Neurol Neurosurg Psychiatry 1971;34:185-91.

31 Nielsen VK, Kardel T. Delayed decrement of the nerve impulse propagation during induced limb ischaemia in chronic hepatic failure. J Neurol Neurosurg Psychiatry 1975;38:966-76.

32 Low PA, Schmelzer JD. Peripheral nerve conduction studies in galactose-poisoned rats. Demonstration of increased resistance to ischemic conduction associated with endoneurial edema due to sugar alcohol accumulation. J Neurol Sci 1983;59:415-21.

33 Ritchie JM. A note on the mechanism of resistance to anoxia and ischaemia in pathophysiological mammalian myelinated nerve. $J$ Neurol Neurosurg Psychiatry 1985;48:274-7.

34 Gabbay KH, Merola LO, Field RA. Sorbitol pathway: presence in nerve and cord with substrate accumulation in diabetes. Science 1966;151:209-10.

35 Greene DA, De Jesus PV Jr, Winegrad AI. Effect of insulin and dietary myoinositol on impaired peripheral motor nerve conduction velocity in acute streptozotocin diabetes. J Clin Invest 1975;55:1326-36. 